\title{
Investigating cold based summit glaciers through direct access to the glacier base: a case study constraining the maximum age of Chli Titlis glacier, Switzerland
}

\author{
Pascal Bohleber ${ }^{1,2}$, Helene Hoffmann ${ }^{2}$, Johanna Kerch ${ }^{2,3}$, Leo Sold ${ }^{4, a}$, and Andrea Fischer ${ }^{1}$ \\ ${ }^{1}$ Institute for Interdisciplinary Mountain Research, Austrian Academy of Sciences, Innsbruck, Austria \\ ${ }^{2}$ Institute of Environmental Physics, Heidelberg University, Heidelberg, Germany \\ ${ }^{3}$ Alfred Wegener Institute Helmholtz Center for Polar and Marine Research, Bremerhaven, Germany \\ 4 independent researcher \\ ${ }^{\text {a }}$ formerly at: Department of Geosciences, University of Fribourg, Fribourg, Switzerland
}

Correspondence: Pascal Bohleber (pascal.bohleber@iup.uni-heidelberg.de)

Received: 15 August 2017 - Discussion started: 28 September 2017

Revised: 19 December 2017 - Accepted: 28 December 2017 - Published: 31 January 2018

\begin{abstract}
Cold glaciers at the highest locations of the European Alps have been investigated by drilling ice cores to retrieve their stratigraphic climate records. Findings like the Oetztal ice man have demonstrated that small ice bodies at summit locations of comparatively lower altitudes may also contain old ice if locally frozen to the underlying bedrock. In this case, constraining the maximum age of their lowermost ice part may help to identify past periods with minimum ice extent in the Alps. However, with recent warming and consequent glacier mass loss, these sites may not preserve their unique climate information for much longer. Here we utilized an existing ice cave at Chli Titlis (3030 m), central Switzerland, to perform a case study for investigating the maximum age of cold-based summit glaciers in the Alps. The cave offers direct access to the glacier stratigraphy without the logistical effort required in ice core drilling. In addition, a pioneering exploration had already demonstrated stagnant cold ice conditions at Chli Titlis, albeit more than 25 years ago. Our englacial temperature measurements and the analysis of the isotopic and physical properties of ice blocks sampled at three locations within the ice cave show that cold ice still exists fairly unchanged today. State-of-the-art microradiocarbon analysis constrains the maximum age of the ice at Chli Titlis to about 5000 years before present. By this means, the approach presented here will contribute to a future systematic investigation of cold-based summit glaciers, also in the Eastern Alps.
\end{abstract}

\section{Introduction}

Glaciers in high-mountain environments are able to archive climate signals in regions and altitudes where other proxy records are scarce. Non-temperate glaciers which archive snow on a quasi-continuous basis can hold past climate and environmental signals that can be retrieved by drilling ice cores. In a number of pioneering studies it has already been shown that, given the climate conditions and altitude range of the European Alps, cold firn and ice areas suitable for ice core studies are located in the uppermost summit ranges (typically above $4000 \mathrm{~m}$ a.s.l.), mostly in the Western Alps (e.g., Haeberli, 1976; Oeschger et al., 1977; Haeberli and Alean, 1985). In comparison, summit glaciers of lower altitudes (typically between 4000 and $3000 \mathrm{~m}$ a.s.l.) received less attention regarding their role as climate archives, until Haeberli et al. (2004) proposed and performed initial investigations of cold ice in detail for the European Alps. Among other findings, the discovery of the Oetztal ice man at Tisenjoch (3210 $\mathrm{m}$ a.s.1.) and the subsequent dating to more than 5000 years before present (Baroni and Orombelli, 1996; Kutschera and Müller, 2003) demonstrated that old ice can be preserved at comparatively lower altitudes under certain conditions. First and foremost these conditions require little to no ice flow, as favored through locations near ice divides, certain bedrock geometries (e.g., depressions) and, most importantly, basal ice temperatures persistently below the pressure melting point ensuring that the ice is frozen to the underly- 
ing permafrost bedrock. A key concept here is that constraining the age of the (stagnant) lowermost layer at the summit may indicate the maximum age of these ice bodies. In contrast, warm-based conditions, e.g., comprising lubrication by meltwater and basal melting, are generally unfavorable for preserving the oldest ice at the base of a glacier. At warmbased sites it is therefore impossible to date the onset of the most recent phase of glaciation. Current warming conditions pose an immediate risk of cold-based sites becoming warmbased and thereby losing this archive (see the discussion of Haeberli et al., 2004, regarding the strong impact of the 2003 summer on Piz Murtèl). Attempting a systematic investigation of cold-based summit glaciers promises important paleoclimatic information on warm periods involving minimum ice extents in the Alps. This would be complementary information to techniques such as the dendro-chronological analyses of trees formerly buried by glacier advances that usually provide evidence of glacier fluctuations at lower elevations (i.e., in the vicinity of the former glacier tongue) (Ivy-Ochs et al., 2009; Joerin et al., 2008; Nicolussi and Patzelt, 2000). In addition, a systematic investigation of cold-based summit glaciers could also provide additional constraint to the question if today's glacier covered highest elevation have been ice free during the Holocene. Such a systematic study essentially requires (i) the identification of cold-based summit sites throughout the Alpine region. Promising candidates for holding cold ice can be identified based on glacio-meteorological parameters including mean annual air temperature, aspect and snow accumulation. (ii) Evidently, obtaining access to the lowermost ice parts is essential, i.e., for direct measurements of englacial temperature and ice sampling. (iii) Constraining the age of the presumably oldest ice is needed. Since the stratigraphy of the expected glacier types (usually mostly made from congelation ice) cannot be expected to include layers of every single year, conventional dating methods like annual layer counting are severely hampered and, as a result, age constraints must be obtained mostly from radiometric methods (May, 2009). Novel developments in adapting and refining radiocarbon techniques for microscopic organic material from glacier ice (Hoffmann et al., 2017; Uglietti et al., 2016) are now available to offer an indispensable dating tool in this context. This is especially the case since the expected glacier age falls within the age range for the application of the radiocarbon technique, e.g., as indicated by the dating of the Oetztal ice man. Combining glaciological surveying (e.g., mass balance, ground-penetrating radar) with radiocarbon dating of ice samples limits the glacier age, especially if direct access to the lowermost ice section can be obtained for sampling at large volume, e.g., through an ice cave (Ødegård et al., 2017). This is especially important for application of the ${ }^{14} \mathrm{C}$ technique, which in ice core science is often hampered by limited sample sizes and low organic carbon concentrations.

Here we report on an investigation designed as a pilot study to a systematic investigation of cold-based summit

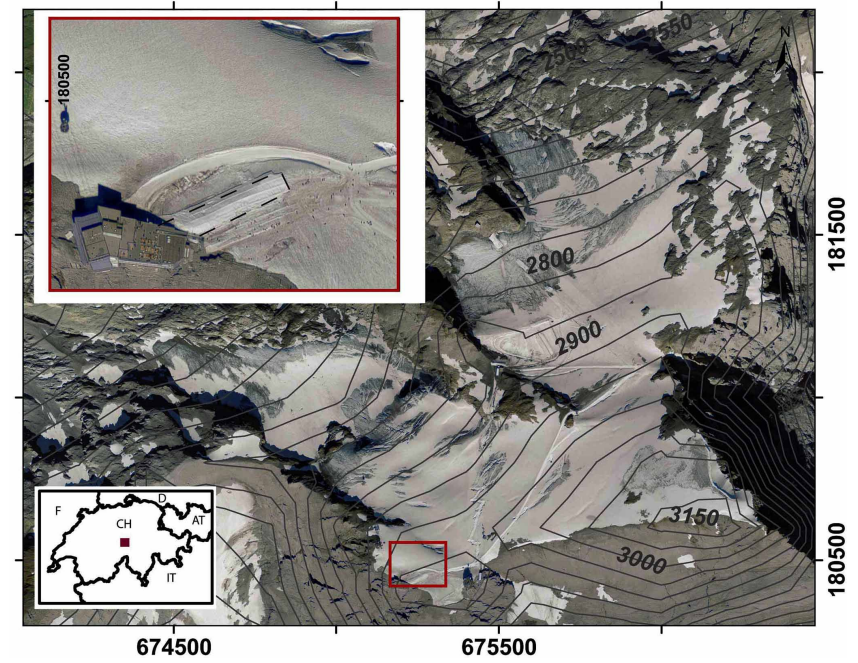

Figure 1. The study site on Titlis glacier, central Swiss Alps. The ice tunnel is adjacent to the cable car station on Chli Titlis summit (red square in overview map). The enlargement corresponds to the red square, and the broken black line shows the position of the ice tunnel under the glacier surface. Note the lighter shading of the surface above the ice tunnel due to surface covers. The orthophotos and elevation data have been kindly provided by Swisstopo (Swissimage and DHM25/200; swi, 2017a, b). GPS coordinates are reported in the Swiss grid system.

glaciers in the Eastern Alps. For this purpose we selected Chli Titlis glacier, located at $3030 \mathrm{~m}$ a.s.l. in the central Swiss Alps (Fig. 1) as the target site. This choice was motivated by considering that, at Chli Titlis, (i) direct access to the lowermost ice parts can be obtained at low logistical cost even for obtaining large sample volumes, enabled through cable car access and an ice tunnel dug along bedrock for touristic purposes; (ii) previous work has already demonstrated cold ice conditions, albeit more than 25 years ago (Haeberli et al., 1979; Lorrain and Haeberli, 1990); and (iii) in an ice cave, direct observations of the ice stratigraphy offer a more detailed picture of settings and potential processes than a small subsample obtained from an ice core.

\section{Site characteristics and previous work}

Glaciological investigations of the summit glacier at Chli Titlis started some 30 years ago in connection with the construction of a telecommunication tower (Haeberli et al., 1979). The cornice-type summit holds the glacier on its north-facing slope, the lee side (Fig. 1). The summit itself features a tunnel through the bedrock connecting the cablecar station with the telecommunication tower. Another tunnel was dug for tourist purposes around $100 \mathrm{~m}$ into the ice along bedrock starting at the cable car station. Ice/firn thickness increases towards the end of the tunnel, where meltwater percolation through small crevasses was reported by Hae- 
berli et al. (2004). The authors also mention well-layered ice roughly $25 \mathrm{~m}$ thick and that accumulation rates on the flat summit area generally seem to be low. According to Haeberli et al. (2004), the existence of old ice at depth appears likely due to negative temperatures reaching far into the underlying bedrock and basal flow velocity close to zero. From sampling ice at the ice-bedrock interface, Lorrain and Haeberli (1990) found a distinct shift towards more negative values in the stable water isotopologues $\left(\delta^{18} \mathrm{O}\right.$ and $\left.\delta \mathrm{D}\right)$. Although Lorrain and Haeberli (1990) doubt an Ice Age origin as the cause of this signal, the peculiar isotopic signature is nonetheless an important marker of the basal ice section, also found in other alpine glacier ice bodies (Wagenbach et al., 2012). Notably the term "basal ice" commonly refers to a thin ice layer with properties characterized primarily by processes operating at the bed (Hubbard et al., 2009; Knight, 1997). We adopt this terminology here and use the term "lowermost ice section" to refer to the deepest ice sections in close vicinity to the bed, which includes parts still unaffected by ice-bed interaction, however. In our study we made an attempt to re-find the isotope anomaly, assuming that the isotope anomaly could only be preserved under cold and stagnant ice conditions, i.e., becoming temperate and/or enhanced ice flow would have likely erased this isotopic signature over the last 25 years.

\section{Methods}

A total of three campaigns were conducted in January 2014, January 2015 and August 2015. Three profiles of ice blocks cut using a chainsaw were obtained from three different locations in the cave. Two profiles were cut out near the entrance of the cave, aiming to be close to the original sampling location by Lorrain and Haeberli (1990). The third profile was located about $20 \mathrm{~m}$ deeper in the cave (Fig. 2). All profiles were cut down to bedrock at locations where the ice-bedrock interface is clearly visible. Individual blocks were cut around $20 \mathrm{~cm}$ deep into the wall and varied, depending on the profile, between 10 and $20 \mathrm{~cm}$ and 8 and $17 \mathrm{~cm}$ in height and width, respectively (Fig. 1).

\subsection{Englacial temperature}

Based on their earlier reconnaissance, Haeberli et al. (2004) reported sub-zero bedrock temperature and temperatures around $-1{ }^{\circ} \mathrm{C}$ in the ice tunnel, with an increase towards the end of the tunnel. Nowadays, active cooling is performed by ventilation of cold outside air into the ice tunnel, especially due to the cave being highly frequented by tourists. Additional anthropogenic technical measures include covering the glacier section hosting the ice tunnel with fabric during the summer season. Today's conditions at Chli Titlis are characterized by clear signs of a negative mass balance at the summit. For example, the fabric-covered section substantially exceeds uncovered neighboring glacier sections in local thick- ness (Fig. 1). The glacier has a remaining thickness of 7$8 \mathrm{~m}$ above the ice cave (Christoph Bissig, Bergbahnen TitlisEngelberg, personal communication, 2017).

Only basic temperature measurements at about $10-15 \mathrm{~cm}$ depth in the ice wall could be performed during the initial reconnaissance campaign in January 2014. At the location of profile 1 , a vertical profile of nine holes was drilled for temperature measurements at $20 \mathrm{~cm}$ vertical intervals. In the follow-up campaign in January 2015, two holes were drilled nearly horizontal by means of a stream drill (drilling slightly upward to let meltwater drain) just above bedrock roughly $2.6 \mathrm{~m}$ deep, at locations 1 and 3 (Fig. 2). Temperature was measured by means of a negative temperature coefficient thermistor chain attached to a solid probe that was inserted into the boreholes. Calibration of the thermistors was done in an ice-water bath at $0^{\circ} \mathrm{C}$. The quality of the temperature measurements is further determined by the data logger and the physical properties of the involved thermistors and cables. Based on earlier studies using the same instruments we estimate the maximum total accuracy to be $\pm 0.2^{\circ} \mathrm{C}$ (see Hoelzle et al., 2011). Temperature readings were taken from the first thermistor at the end of the chain, i.e., at the deep end of the boreholes. To reduce latent heat effects that stem from drilling the borehole and to allow for the thermal adjustment of the thermistors, readings were taken at intervals of 4-10 min and were logged over 40-60 min. For all boreholes, this was sufficient to attain temperature fluctuations at least 2 orders of magnitude smaller than the estimated measurement accuracy.

\subsection{Stable water isotopes}

All ice samples were stored in coolers with thermal packs and transported in frozen condition to the Institute of Environmental Physics, Heidelberg University (IUP-HD), for further analyses. The outermost $10 \mathrm{~cm}$ of each block exposed to the tunnel was removed. The opposite, i.e., inside-facing, side of each block was used to obtain samples for stable water isotope analysis. Initially, each block was sampled at coarse resolution between 7 and $10 \mathrm{~cm}$ in distance along the vertical axis. To investigate lateral variability within the blocks, each coarse sample was further divided along its vertical axis (denoted samples A and B). The lowest $25 \mathrm{~cm}$ of profile 1 were cut at higher resolution (around $2 \mathrm{~cm}$ ). Small uncertainty in assigning a distance above bedrock may be caused by the slightly irregular block shape (round edges) and was estimated as accumulating to a few $\mathrm{cm}$ at most. All samples were analyzed using conventional mass spectrometry $\left(\delta^{18} \mathrm{O}\right.$ only) at IUP-HD. In Fig. 3 the average of samples A and B is plotted against height above bedrock, using the absolute range in isotope values to indicate the lateral isotope variability. No stable isotope data are available for block 2-5 in profile 2 (see respective data gap in Fig. 3). In order to obtain data for both water isotopes, $\delta^{18} \mathrm{O}$ and $\delta \mathrm{D}$, additional measurements were performed using a Picarro cavity ring- 


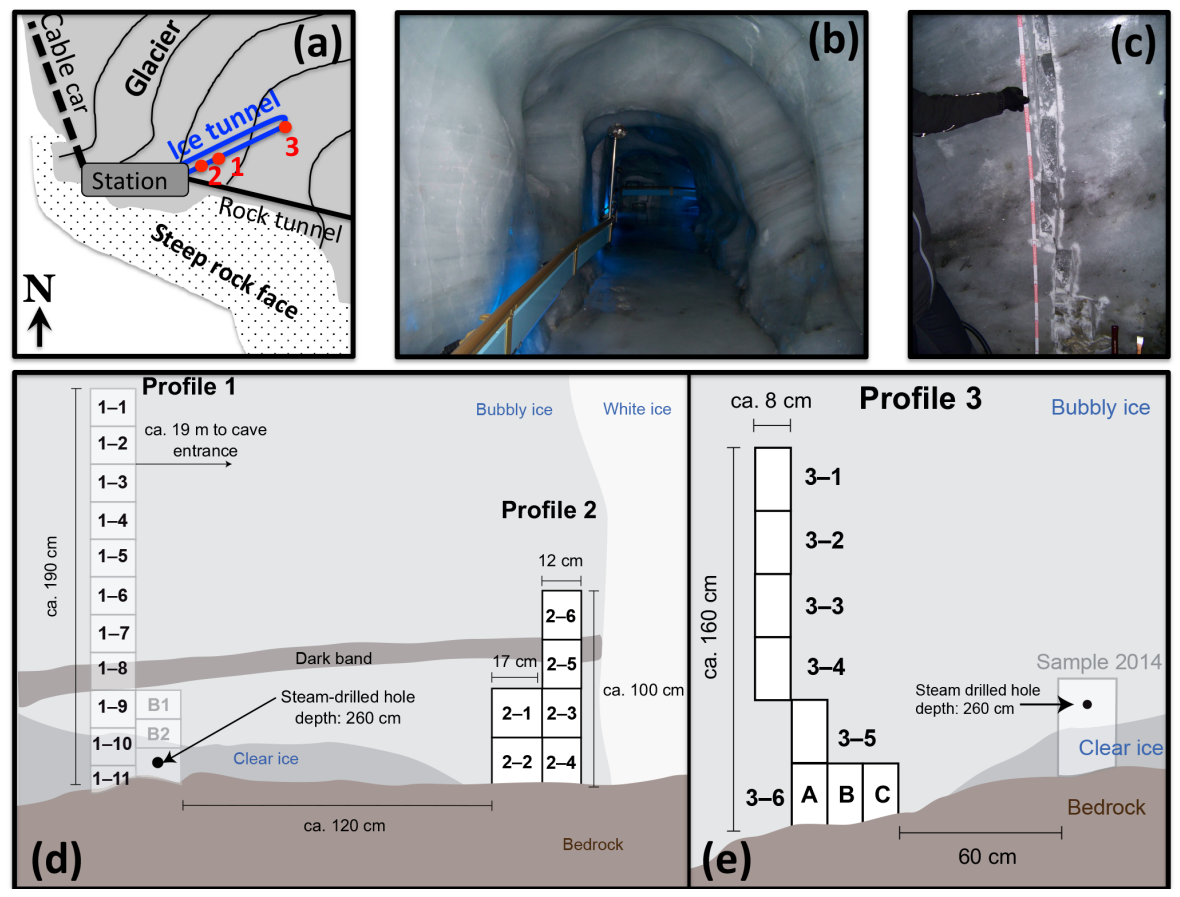

Figure 2. Overview on ice sampling at the Chli Titlis glacier. Panel (a) shows a schematic diagram with ice sampling locations within the ice tunnel. Distinct near-horizontal layering is visible within the tunnel (b). A total of three ice block profiles were cut by chainsaw down to bedrock (c). Panels (d, e) present schematic details on the ice block sampling. Note that two additional blocks (2-7 and 2-8) were cut in parallel behind block $2-4$.

down spectrometer at IUP-HD. Co-isotopic measurements comprised all samples of profile 1 and, in addition, samples at high resolution (around $2 \mathrm{~cm}$ ) of profile 2. Measurement uncertainties range within \pm 0.1 and $\pm 0.4 \%$ ofor $\delta^{18} \mathrm{O}$ and $\delta \mathrm{D}$, respectively. However, due to technical difficulties with the instrument at the time of measurement $\delta \mathrm{D}$ values of profile 1 are associated with larger uncertainty (up to $4 \%$ ) and hence were not further used in this study.

\subsection{Radiocarbon dating}

For radiocarbon dating five different ice blocks have been analyzed using the microscopic particulate organic fraction (POC). Two blocks each were selected of profiles 1 and 2, and an additional block of profile 3 (Table 1). The ice samples were melted, the POC was filtered, combusted into $\mathrm{CO}_{2}$ and the radiocarbon content was measured via an accelerator mass spectrometer utilizing a gas ion source. Details on POC extraction and ${ }^{14} \mathrm{C}$ measurement can be found in Hoffmann et al. (2017). Visible dark layers and sediment-contaminated parts were carefully avoided during sub-sampling. Upon processing for ${ }^{14} \mathrm{C}$ analysis, all samples exhibited a thick layer of very black and highly organic material on the filter surface after filtration. Samples 2-3 and 2-6 were combusted at $340^{\circ} \mathrm{C}$. Samples 1-2, 1-9 and 3-5 were combusted at $800^{\circ} \mathrm{C}$. It is important to point out that due to different combustion temperatures of multiple organic species and increasing in- fluences of aged and decomposed organic material (reservoir effect), higher combustion temperatures can lead to higher ${ }^{14} \mathrm{C}$ ages. In a separate investigation parallel to the work presented here, a combustion temperature of $340^{\circ} \mathrm{C}$ for POC was determined as the best way to avoid reservoir effects caused by influences of already aged material incorporated into the sample and hence yields the best representation of the actual ice sample age (Hoffmann et al., 2017). Accordingly, the retrieved ages for the $800^{\circ} \mathrm{C}$ combustion temperature samples are regarded as upper age limits only.

\subsection{Visual stratigraphy and physical ice properties}

The macroscopic characteristics of the stratigraphy within the tunnel were recorded visually, with special emphasis on the three sampling locations. The ice generally has a high density in small bubbles, giving it the white appearance typical for glacier ice. The walls show distinct thin (millimeter-centimeter thick) bubble-free layers and, less abundant, yellow-brown dust-like layers. Towards the entrance of the tunnel, at the location of profile 1 and 2, layering is near horizontal and parallel to bedrock. At this site the stratigraphy also features a distinct layer rich in dust and sand-like material, giving it a dark appearance with respect to the surrounding layers (thus we refer to it as a "dark band" here). At the far end of the tunnel (profile 3), the layers are substantially inclined. The deepest part of profile 1 showed a 
Table 1. POC ${ }^{14} \mathrm{C}$ dating results for the samples from Titlis glacier cave. The sample names denote the profile and the block number as indicated in Fig. 2. The additional temperature in the sample name refers to the POC combustion temperature. The $\mathrm{F}^{14} \mathrm{C}$ value is given according to the convention stated in Stuiver and Polach (1977). The calibrated ages have been calculated using OxCal version 2.4 (Ramsey, 1995). All calibrated ages are reported as their $1 \sigma$ ranges in years before present (1950 CE).

\begin{tabular}{lrrrr}
\hline $\begin{array}{l}\text { Block } \\
\text { number }\end{array}$ & $\begin{array}{r}\text { Combustion temperature } \\
\left({ }^{\circ} \mathrm{C}\right)\end{array}$ & $\begin{array}{r}\mathrm{POC} \text { mass } \\
(\mu \mathrm{gC})\end{array}$ & $\mathrm{F}^{14} \mathrm{C}$ & $\begin{array}{r}\text { Calibrated age } \\
(\text { years BP })\end{array}$ \\
\hline $1-2$ & 800 & 96.5 & $0.848 \pm 0.008$ & $1180-1305$ \\
$1-9$ & 800 & 47.7 & $0.702 \pm 0.007$ & $2861-3070$ \\
$2-3$ & 340 & 43.6 & $0.610 \pm 0.009$ & $4237-4615$ \\
$2-6$ & 340 & 20.1 & $0.754 \pm 0.009$ & $2122-2378$ \\
$3-5$ & 800 & 56.2 & $0.568 \pm 0.009$ & $5047-5319$ \\
\hline
\end{tabular}

basal section of very clear, i.e., bubble-free, ice. This clear ice section at the base extended through a larger part of the cave, but was present at neither profile 2 nor 3 (Fig. 2). For further description of the visual stratigraphy and macroscopic characteristics of the sampling sites in the ice tunnel, we summarize the stratigraphic properties in Table 2, adopting the scheme of Hubbard et al. (2009) for ice facies classification.

To obtain complementary information about the microscopic physical ice properties, thick and thin section samples were prepared from four blocks of profile 1, from a sample of the clear basal ice in the back of the tunnel, and from one block of profile 2. The sections are analyzed using a large-area scanning macroscope (LASM, Schaefter+Kirchhoff $\mathrm{GmbH}$ ) to obtain microstructure maps of grain boundaries (GB) and bubbles, and with an automated fabric analyzer (FA, Russell-Head Instruments), which provides the crystallographic orientation of individual ice crystals in a thin section sample. An overview of the samples is given in Table 3. The fabric analyzer data were automatically processed (Eichler, 2013) and provide estimates for grain size and crystal-preferred orientation (CPO). The microstructure maps are qualitatively evaluated and discussed below.

\section{Results and discussion}

\subsection{Englacial temperature}

The initial temperature measurements (in 2014) in shallow horizontal boreholes (mechanical drilling) showed little variability within the vertical profile, with $-2.3{ }^{\circ} \mathrm{C}$ at about $1.8 \mathrm{~m}$ above bedrock, $-2.2^{\circ} \mathrm{C}$ just above bedrock and the average over nine different measurements around $-2.3{ }^{\circ} \mathrm{C}$. Notably, even the shallow measurements differed unambiguously from the air temperature in the ice tunnel, which was measured at $-1.5^{\circ} \mathrm{C}$. The subsequent measurements in the deeper horizontal boreholes $(2.6 \mathrm{~m}$, thermal drilling) at locations of the isotope profiles 2 and 3 revealed -2.9 and $-2.6^{\circ} \mathrm{C}$, respectively, in January 2015 . For comparison, the temperature measurement was repeated in high summer, showing $-1.9^{\circ} \mathrm{C}$ at profile 2 in August 2015, which is still substantially below zero. It is worth noting that (i) due to the limited ice thickness an influence of seasonal temperature variability may be present at the bed, and (ii) the englacial temperatures measured in this study are systematically below the values reported by Lorrain and Haeberli (1990) (e.g., $-1{ }^{\circ} \mathrm{C}$ at the entrance of the tunnel), potentially connected to today's artificial cooling of the tunnel. Our results demonstrate that sub-zero englacial temperatures very likely prevail at our sampling sites in the ice tunnel, although the values should be considered as upper limit estimates. This is (i) due to the limited time for establishing equilibrium and latent heat effects from drilling of the borehole and (ii) because of the higher air temperature in the ice tunnel that affects air temperature in the borehole and the temperature of the surrounding ice.

\subsection{Stable water isotopes}

As already stated above, the stable water isotope data primarily served as a general stratigraphic marker and, more importantly, were specifically investigated with respect to refinding the outstanding basal isotope signature. The isotope data of the three profiles are presented against height above bedrock in Fig. 3. The average levels in $\delta^{18} \mathrm{O}$ are -13.35 , -14.45 and $-14.54 \%$ for profiles 1,2 and 3 , respectively, thus broadly consistent with the values reported by Lorrain and Haeberli (1990). Although the coarse resolution isotope levels are very similar among the upper parts, the profiles differ significantly regarding their basal section. While no outstanding signal with respect to the rest of the profile is found in profile 3 (albeit available only at coarse resolution) the lowermost $10-20 \mathrm{~cm}$ of profile 1 and 2 comprise more enriched and depleted values, respectively. In profile 1 , the lowermost $15 \mathrm{~cm}$ coincide with the basal layer visibly clear and free of bubbles (see Fig. 2). The isotopic values of this section show little variability with respect to the rest of the profile, except for a stepwise increase by roughly $3 \%$ within the last $5 \mathrm{~cm}$ of the profile. Profile 2, on the other hand, features a gradual rise in $\delta^{18} \mathrm{O}$ values between 40 and $20 \mathrm{~cm}$ above bed, followed by a sharp drop by about $2 \%$ within 
Table 2. Macroscopic characteristics of the ice facies at the locations of the three profiles in the ice tunnel at Chli Titlis. The facies/ice type classification is based on the scheme of Hubbard et al. (2009). Height refers to the distance above bedrock.

\begin{tabular}{|c|c|c|c|c|}
\hline Height (cm) & Bubble content & Debris content & Internal layering & Ice type \\
\hline \multicolumn{5}{|l|}{ Profile 1} \\
\hline 190-79 & Very high, small bubbles & Very low, sand & Thin, bubble-free, sand, near horizontal & Glacier ice \\
\hline $79-41$ & Very high, small bubbles & Low, mainly sand & None & Glacier ice \\
\hline $41-15$ & Very high, small bubbles & Very low, sand & None & Glacier ice \\
\hline $15-0$ & Very low & Low, silt and sand, some gravel & None & Clean \\
\hline \multicolumn{5}{|l|}{ Profile 2} \\
\hline $100-70$ & Very high, small bubbles & Very low, sand & Thin, bubble-free, sand, near horizontal & Glacier ice \\
\hline $70-63$ & Very high, small bubbles & Low, mainly sand & None & Glacier ice \\
\hline $63-3$ & Very high, small bubbles & Very low, sand & None & Glacier ice \\
\hline $3-0$ & Low & Low, silt and sand, some gravel & None & Clean \\
\hline \multicolumn{5}{|l|}{ Profile 3} \\
\hline $160-90$ & Very high, small bubbles & Very low sand & Some sand, inclined (ca. $30^{\circ}$ ) & Glacier ice \\
\hline $90-70$ & Very high, small bubbles & Low, diamicton & Heterogenous debris & Dispersed \\
\hline $70-30$ & Very high, small bubbles & Low, some gravel & None & Glacier ice \\
\hline $30-0$ & Low & Low, diamicton & None & Dispersed \\
\hline
\end{tabular}

Table 3. Overview of measurements of physical properties of ice samples from Chli Titlis. Indicated are sample and measurement type, i.e., using a large-area scanning macroscope (LASM) and fabric analyzer (FA).

\begin{tabular}{llll}
\hline Block number & Type of thin section & LASM & FA \\
\hline $1-9$ & 2 vertical sections $(6 \times 7 \mathrm{~cm})$ & yes & yes \\
$1-10$ & 2 vertical sections $(7 \times 9 \mathrm{~cm})$ & yes & yes \\
$1-11$ & 1 vertical section, from clear ice $(7 \times 8 \mathrm{~cm})$ & yes & no \\
$1-B 1$ & 1 vertical sections from the side $(5 \times 10 \mathrm{~cm})$ & yes & yes \\
$3-2014$ & horizontal section, just above clear ice $(6 \times 9 \mathrm{~cm})$ & yes & yes \\
$2-7$ & 2 sections in orthogonal planes: & yes & no \\
& 1 vertical section from the back $(7 \times 10 \mathrm{~cm})$, & & \\
& 1 vertical section from the side $(10 \times 11 \mathrm{~cm})$ & & \\
\hline
\end{tabular}

the lower $20-15 \mathrm{~cm}$. The differences in basal isotope signature between profile 1 and 2 are also reflected in different visual and microstructural properties (see below). With values around $-16 \%$ just before bedrock (clearly outside of the range of the rest of the profile), the basal isotope signature of profile 2 is in near-perfect agreement with the phenomenon described by Lorrain and Haeberli (1990). Sampling an adjacent block of roughly the same depth at the location of profile 2 reproduces this anomaly, confirming its presence at this location (see grey line in Fig. 3). A basal isotope signature characterized by a gradual enrichment followed by distinct depletion in isotope values has been also observed at various other mountain ice core drilling sites, in particular at Colle Gnifetti and Mont Blanc (Wagenbach et al., 2012). The signature is unlikely to be of pure atmospheric origin, but rather the result of post-depositional effects being involved (Keck, 2001). An adequate investigation of this intriguing phenomenon remains outside the scope of the present work.
However, the re-discovery of the isotope anomaly initially described at Chli Titlis by Lorrain and Haeberli (1990) is significant in the following sense: its unchanged presence since the last 25 years strongly indicates that the basal ice has not undergone substantial changes as would be expected if having become temperate or under significant basal ice movement. Using the $\delta \mathrm{D}$ values available for profile 2 we also performed a co-isotopic analysis (Fig. 4). Calculating ordinary linear regression of $\delta \mathrm{D}$ against $\delta^{18} \mathrm{O}$ yields a slope of $(7.7 \pm 0.2,1$ standard error) at a correlation coefficient of $r=0.99$. These values are nearly identical to the previous investigation (Lorrain and Haeberli, 1990) and do not show clear signs of isotopic change after ice formation (e.g., by melting and refreezing) for this part of the stratigraphy.

\subsection{Visual stratigraphy and physical ice properties}

Except for the basal ice section, the visual stratigraphy at profiles 1 and 2 comprised bubble-rich glacier ice with dis- 


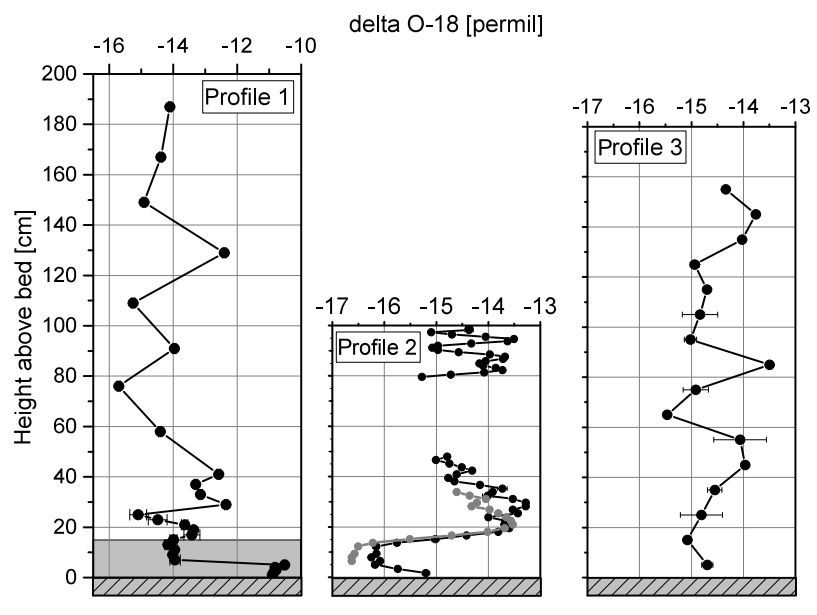

Figure 3. Stable water isotope profile of the three sampling locations. Profile 2 reproduces the basal anomaly previously described by Lorrain and Haeberli (1990). The grey plot shows measurements of a neighboring block. The data gap in profile 2 corresponds to block 2-5, for which isotope measurements are not available. Note that the comparatively less negative isotope values close to bedrock in profile 1 correspond to the layers with clear ice (grey shading; see text). The basal isotope signal in profile 3 does not show outstanding values with respect to the rest of the profile. Error bars denote the range in values from two adjacent samples that were analyzed and the results averaged (profile 1 and 3 ).

tinct layers composed of bubble-free and dust-rich ice (see Table 2). We interpret the layers as representing former surface conditions, e.g., soil or dust-like material deposited on the surface. Likewise the bubble-free sections represent layers of refrozen meltwater. Notably all layers are near horizontal, parallel to the bed and do not show any signs of folds or other stratigraphic disturbances. As a characteristic feature, we find the above-mentioned distinct dark band running through profiles 1 and 2. The dark band is thicker than the dust-like layer above, but does not feature different types of debris, e.g., mainly sand and no gravel. The visual stratigraphy at profile 3 also shows bubble-rich glacier ice but, in comparison to the section near the entrance of the tunnel (profiles 1 and 2), differs by showing inclined layers and generally a higher content of gravel dispersed within the lower $90 \mathrm{~cm}$ above bed.

To obtain additional information regarding the lower and basal ice sections, all microstructural samples were taken from the lower parts in profiles 1 and 2 . The mean grain size (i.e., ice crystal size), derived from the FA images, lies between 0.55 and $2.4 \mathrm{~cm}^{2}$ but the largest grains cover between 10 and $20 \mathrm{~cm}^{2}$. The grains show little indication of active deformation (e.g., no abundant subgrain boundaries) and it can be assumed that the large grains are a consequence of normal grain growth, which is the dominant microstructural process in stagnant ice and strongly enhanced by warm temperatures, or migration recrystallization at low strain rates (Faria
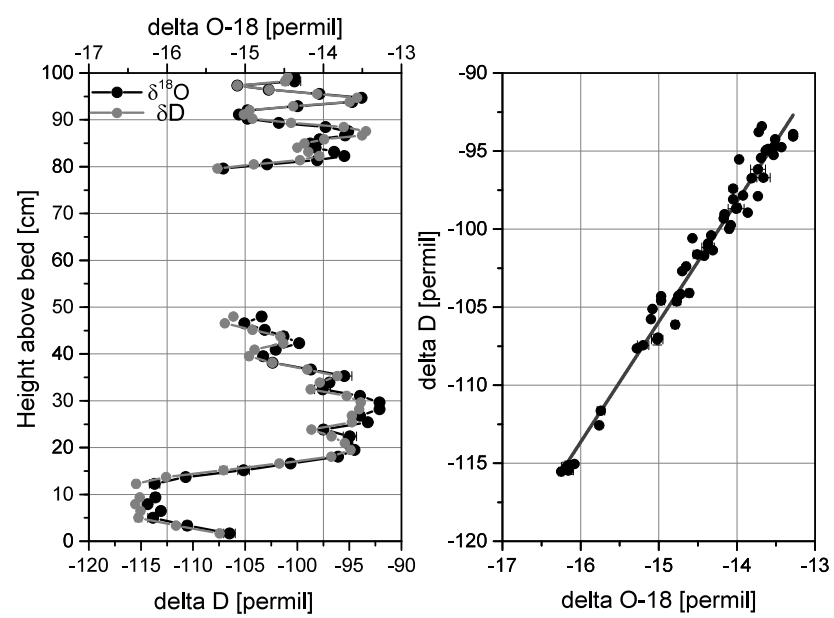

Figure 4. Co-isotopic analysis of profile 2 showing both $\delta \mathrm{D}$ and $\delta^{18} \mathrm{O}$ in grey and black, respectively (left side). Also shown is the linear regression of $\delta \mathrm{D}$ vs. $\delta^{18} \mathrm{O}$, revealing a slope of $(7.7 \pm 0.2)$, in agreement with co-isotopic results previously described by Lorrain and Haeberli (1990).

et al., 2014). While this finding holds for the entire basal section of profile 2, including the lowermost $10 \mathrm{~cm}$, the lowermost $10 \mathrm{~cm}$ of profile 1 (block 11) includes many smaller grains and are characterized by a laminar or elongated grain structure with irregular grain boundaries and almost bubblefree, corresponding to the basal sections visually identified as clear ice (Fig. 5, Table 2). Accordingly, the basal microstructural pattern independently confirms the presence of congelation ice at the base of profile 1 . Additionally, in the basal sample of profile 2 , which was cut perpendicular to the tunnel wall, elongated bubbles (mean aspect ratio of 1.8) inclined at approximately $45^{\circ}$ were observed. This implies that a moderate deformation is to be expected, due to the lacking constraint of the tunnel and/or the decrease in viscosity due to the warm temperatures. The crystal-preferred orientation (CPO) observed in the large-grained samples can be described as a multiple-maxima pattern -i.e., the $c$ axes of the grains are oriented in several clusters around the vertical. This pattern is often found in basal ice close to the melting point in conjunction with coarse grains (Gow and Williamson, 1976; Duval et al., 1983; Alley, 1992).

\subsection{Cold-based ice at Chli Titlis}

Based on our evidence from basal temperature measurements revealing temperatures well below the pressure melting point, a preserved basal isotope anomaly and analysis of physical properties, we conclude that almost stagnant ice frozen to bedrock still exists at Chli Titlis today. This is not to be expected a priori in view of ongoing warming conditions and an ice thickness not large enough to fully dampen seasonal temperature variability. A temperature of only $-0.7^{\circ} \mathrm{C}$ at $15 \mathrm{~m}$ depth was reported in $1979 / 1980$ by Haeberli et al. 


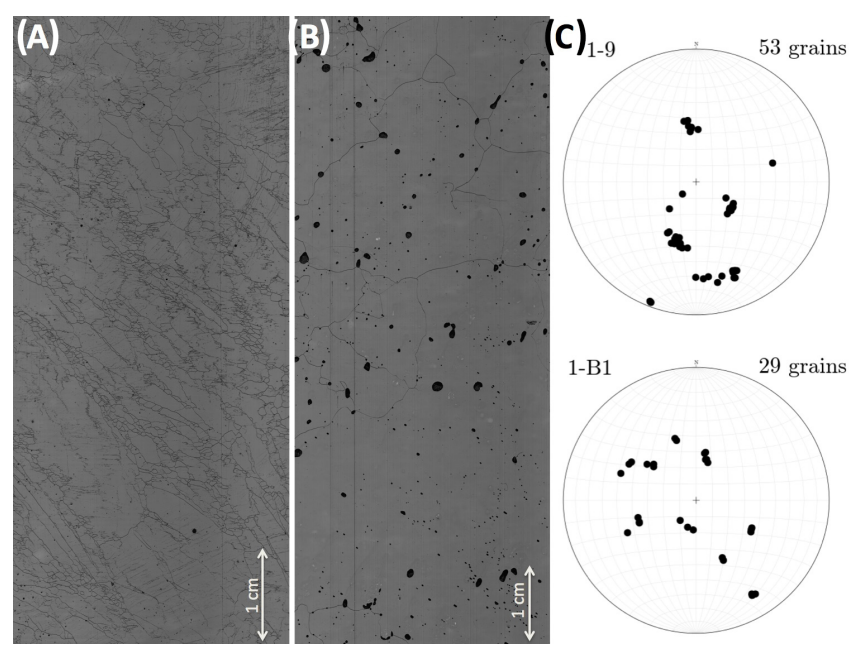

Figure 5. Selected results from microstructural analysis. Two example images of a large-area scanning macroscope (LASM) of ice samples of profile 1 (block 1-11) and 2 (block 2-7) are shown in (a, b), respectively. The basal ice of the two profiles looks distinctly different, with large grains and abundant air bubbles dominating profile 2 (b). In contrast, the lowest $10 \mathrm{~cm}$ of profile 1 is almost bubble-free and show very small elongated grains (a), indicating refrozen meltwater (see text). Schmidt diagrams shown in (c) illustrate the multiple-maxima crystal-preferred orientation of the (nonmeltwater) basal ice.

(1979) at the summit firn of Chli Titlis, and a temperature inside the ice tunnel of around $-1{ }^{\circ} \mathrm{C}$ reported in 1990 (Lorrain and Haeberli, 1990). At the same time, atmospheric warming trends of the past decades are reflected in rising englacial temperatures even at the highest glaciers above $4000 \mathrm{~m}$ a.s.l. in the Western Alps (Gilbert and Vincent, 2013; Hoelzle et al., 2011). Titlis glacier is reported to show a negative mass balance for the time period 1986-2010 (Zemp et al., 2015), consistent with evidence for negative mean geodetic mass balance of Swiss glaciers between 1980 and 2010, extending to locations above $3500 \mathrm{~m}$ a.s.l. (Fischer et al., 2015). No direct mass balance measurements with stakes close to the ice cave have been carried out. The glacier-wide mass balance data provide only limited information regarding the mass balance at the ice cave, but this is enough to draw a general picture. A comparison to other glaciers at similar elevations would have to take into account the local climatological settings (Abermann et al., 2011) and, in addition, stake measurements in summit locations are generally sparse. In the Eastern Alps, mass balance is measured for the full altitude range with stakes on Kesselwandferner in Oetztal Alps. The stake L8, located at much the same altitude in a similar climatic setting to Chli Titlis, changed from being close to ELA (equilibrium line altitude) to increasing mass losses since the mid-1980s (Fischer et al., 2014).

The above evidence suggests that the ongoing change may have also affected the lowermost ice sections at Chli Titlis over the past decades. However, making a straightforward connection between atmospheric warming trends and conditions in the ice cave suffers from a great deal of complexity, connected to the surface mass and energy balance and, in particular, anthropogenic technical measures. Investigation of ice masses in karst caves pointed out that mass and energy balance in cave systems is more intricate (Schöner et al., 2011; Obleitner and Spötl, 2011) than for a glacier without englacial cavities as it would be the case when drilling an ice core. For instance, this potential warming influence is counteracted by ongoing efforts to actively control the air temperature in the ice tunnel and to protect the surface from ablation, which may contribute to keeping the ice frozen to bedrock. Since the tunnel is located in a ski area, substantial reworking of the surface snow cover takes place in its vicinity. Surface covers reduce ablation (Fischer et al., 2016) and alter the surface energy balance mainly by reducing the direct incoming solar radiation (Olefs and Lehning, 2010). The propagation of these changes in energy balance into the glacier, and potential changes in the ice temperatures have only been investigated in a depth of $3 \mathrm{~m}$ ice on Schaufelferner in the Stubai Alps with temperatures close to $0{ }^{\circ} \mathrm{C}$ during summer. No significant differences between minimum ice temperatures of covered and uncovered areas had been evident then. Trying to disentangle these anthropogenic technical measures from natural effects is difficult. However, the above considerations illustrate the complexity of the situation, while raising doubts as to what extent the cold-based ice conditions would have been preserved without the current technical measures. Predicting the future fate of Chli Titlis glacier would certainly require a separate dedicated investigation including a multi-annual logging of a full englacial temperature profile at the site.

\subsection{Constraining the maximum age of Chli Titlis ice}

Basal melting and non-stagnant basal ice flow fundamentally hamper the preservation of old ice at the bed of glaciers with warm-based conditions. Consequently, a cold-based thermal regime is required to preserve ice of substantial age near bedrock at small glaciers like Chli Titlis. Persistent stagnant ice flow conditions may hold the original ice in place after glacier formation. The results of the radiocarbon dating efforts reveal samples with generally very large POC concentrations starting at $500 \mathrm{\mu gC} \mathrm{kg}^{-1}$ of up to almost $4 \mathrm{mgC} \mathrm{kg}^{-1}$ ice. This includes samples without any visible inclusions of particulate material. The POC concentrations are a factor of 10-100 higher than for other high alpine glaciers (e.g., at Colle Gnifetti; Hoffmann, 2016). The organic material is assumed to be of eolian origin originally deposited on the glacier surface. The basal layer, which may contain a substantial amount of sediment from the bed, has been avoided for ${ }^{14} \mathrm{C}$ analysis. The high POC concentrations result in relatively small statistical ${ }^{14} \mathrm{C}$ counting errors of $1-2 \%$ and also no significant influences of process blanks are expected. 

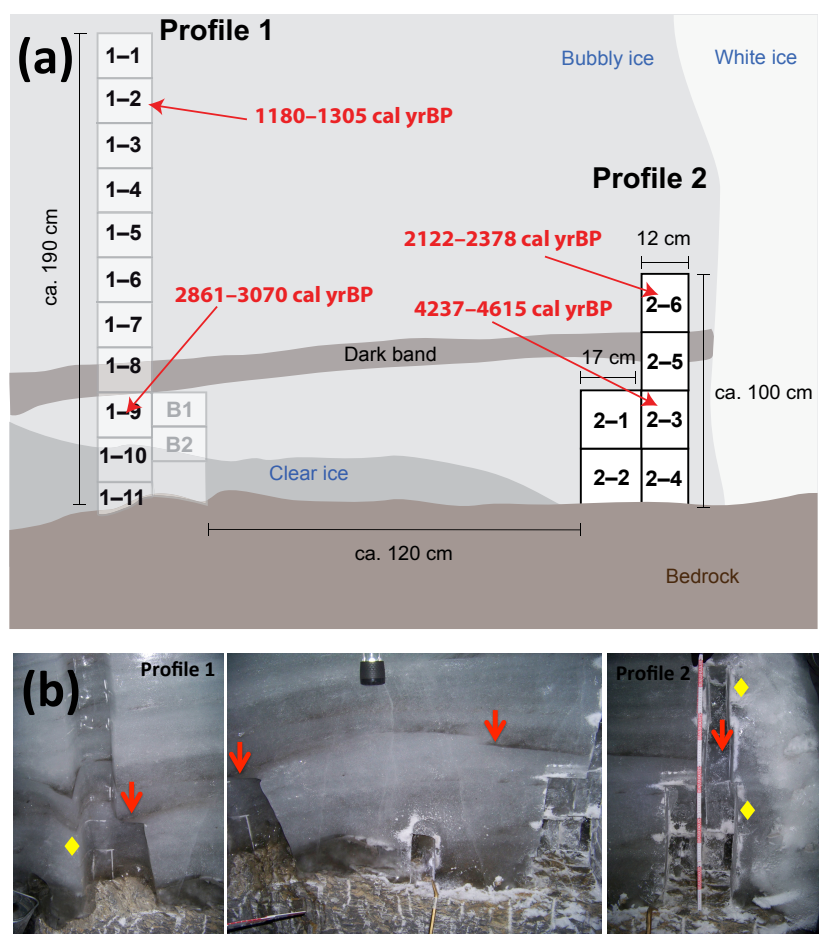

Figure 6. Calibrated radiocarbon ages of profiles 1 and 2 (in red, a). (b) Collection of three pictures taken during the 2015 sampling campaign to illustrate the visual layering between profiles 1 and 2 . The lower end of the visible dark band (indicated by red arrows) is located at about 41 and $63 \mathrm{~cm}$ above bedrock for profile 1 and 2, respectively. Yellow diamonds indicate the location of radiocarbondated samples (see text).

All radiocarbon ages have been calibrated using OxCal 4.2 (Ramsey, 1995). Figure 6 presents the calibrated ages reported with their $1 \sigma$ range and gives an overview of the location of the dated ice blocks of profiles 1 and 2 . We generally find younger ages at greater distance above bedrock in each profile. This suggests a general chronological order of the layers in the ice tunnel wall, which is also expected considering its distinct visible layering free of folding. Tracing the sharp lower edge of the dark band leads from about $63 \mathrm{~cm}$ at profile 2 (roughly at the center of block 2-5) to about $41 \mathrm{~cm}$ at profile 1 (incidentally right at the border between blocks 1-9 and 1-8). It remains difficult from our data to precisely identify the physical cause of the dark band, e.g., whether this layer could be indicating a former hiatus in glacier growth. However, tracing the dark band between profile 1 and 2 suggests that at least parts of the lower $63 \mathrm{~cm}$ of profile 2 are not present at profile 1 . Having found evidence of refrozen meltwater at the base of profile 1 suggests basal melting has potentially played a role in causing this deficit. In this view, it appears reasonable to find block 1-9 at least about 500 years older than block 2-6 but more than 1000 years younger than block 2-3 (at a similar distance above bedrock). However, sample 1-9 was combusted at $800^{\circ} \mathrm{C}$, which may partially contribute to slightly higher ${ }^{14} \mathrm{C}$ ages compared to the samples combusted at $340^{\circ} \mathrm{C}$ (e.g., 2-3 and 2-6). It is worth noting in this context that the maximum ages found at profiles 2 and 3 (both without the bubble-free basal layer) differ only by about 450 years, based on combustion temperatures of 340 and $800^{\circ} \mathrm{C}$, respectively. We took great care in subsampling the ice blocks to avoid any age-biasing contaminants such as old cryoconite or organic sediment. For this reason, the lowest and arguably the oldest samples (roughly the lowest $10-20 \mathrm{~cm}$ ) have not been analyzed for ${ }^{14} \mathrm{C}$, since they show abundant inclusions of small rocks and sediment (although these samples may serve for a future dedicated investigation into age-biasing processes in radiocarbon glacier dating). Taking all this into consideration, the oldest sample (5047-5319 years BP, profile 3) is regarded as representing an upper age limit for ice at Chli Titlis.

The large gradient in age (e.g., for profile 2, several thousand years' difference within less than a $1 \mathrm{~m}$ ) also deserves attention. Numerical flow modeling by Haeberli et al. (1979) indicated the presence of substantial shear near bedrock even close to the summit, making thinning of the lowermost layers a possibility. Results of our ice microstructure analysis are consistent with moderate ice deformation. Notably, deformation by simple shear would primarily entail thinning of layers as opposed to layer folding or turbulent ice flow. As an alternative, considering ice formation at the site, phases of ablation (like observed today) followed by recurring accumulation could also play a role in explaining the observed vertical age gradient. Reconstructing the details of the glacier response to past (and future) climate conditions deserves a separate thorough investigation, e.g., taking into account numerical modeling of ice flow and energy balance. As a potential contribution to such an effort, the results of the study presented here already constrain the maximum age of the ice remaining at the summit of Chli Titlis today.

\section{Outlook}

Based on the above results, promising future contributions can be expected from extending the approach presented here in a more systematic investigation to constrain the age of other summit glaciers, selected with respect to comprising cold-based ice condition, access to lowermost ice parts and geographic coverage (preferably also in the Eastern Alps). Taking as a promising example in this regard, we have also started to investigate the ice of the Schladminger glacier at Hoher Dachstein (Austria). This site offers similar glaciological and ice sampling conditions to Chli Titlis: Schladminger glacier is located at $2700 \mathrm{~m}$ a.s.l. on a cornice-type, north-facing summit, and direct access to ice at bedrock is possible by means of an ice tunnel for tourists. We have employed the same set of tools described here, and found an englacial temperature of $-1.3{ }^{\circ} \mathrm{C}$ at $190 \mathrm{~cm}$ inside the tunnel wall just above bedrock. As a preliminary result, radiocar- 
bon analysis of one of the obtained ice blocks indicates an age around $4297-3715$ years BP ( $1 \sigma$ range), which is, interestingly, close to the age range observed at Chli Titlis.

In their earlier study, Lorrain and Haeberli (1990) had estimated, based on their flow model considerations, that the oldest ice at Chli Titlis is likely of Holocene origin with a maximum age of centuries to millennia. The results of the present study show that this estimation was accurate, but they further demonstrate that in fact the ice clearly reaches several millennia in age. The presence of millennia-old ice in the lowermost sections at Chli Titlis, and the preliminary evidence at Schladminger glacier, is significant from a glaciological perspective, since demonstrating that cold-based summit glaciers around $3000 \mathrm{~m}$ a.s.l. can (still) archive ice of substantial age. In a paleoclimatological context, the maximum age constraints of the ice at Chli Titlis suggest that this location has been ice-covered over roughly the last 5000 years. This finding is in general agreement with widespread evidence of a period of minimal glacier extent throughout the Alps at that time (e.g., Ivy-Ochs et al., 2009; Hormes et al., 2001). This includes evidence from dating archaeological artifacts recovered at other summit locations of comparable altitude, such as possible ice-free conditions at Tisenjoch (3210 $\mathrm{m}$ a.s.l., the location of the Oetztal ice man) (Bonani et al., 1994) and, at greater proximity to Titlis, Schnidejoch pass ( $2730 \mathrm{~m}$ a.s.l.) (Grosjean et al., 2007). Notably the presumed onset of the recent phase of glaciation at Chli Titlis follows the termination of the last "Holocene Optimum Event" (HOE) around 5650 years BP as defined by Joerin et al. (2008). The latter study investigated Tschierva glacier, located in the Eastern Swiss Alps at similar altitude as Chli Titlis, and reports the equilibrium line altitude rising by more than $220 \mathrm{~m}$ to above $3040 \mathrm{~m}$ a.s.l. during the HOE phases. In order to investigate whether the evidence from Titlis and Schladminger glacier points in fact towards a widespread phenomenon of reduced summit glaciers in the time period around 40005000 years BP, it will be intriguing to continue our analysis and to integrate additional Alpine summit glaciers at comparable altitude.

\section{Conclusions}

We have successfully employed a combination of englacial temperature measurements with ice analysis and radiocarbon dating to show that ice frozen to bedrock still exists at Chli Titlis, and we were able to constrain the maximum age of the ice remaining at the summit today. For this purpose we utilized an existing ice cave to directly access, sample and investigate the age, isotopic and physical properties of the lowermost ice layers. Temperature measurements demonstrate basal temperatures that are well below the pressure melting point throughout the year, albeit likely influenced by the air temperature in the tunnel. This finding indicates close-to-stagnant ice frozen to bedrock, substantiated by re- sults from ice microstructure analysis. In addition, the stable water isotope measurements obtained from one profile reproduce a particular basal anomaly found in a study performing the first ice sampling over 25 years ago. Our radiocarbon analysis of five ice blocks suggests a chronological order of the visible ice layers and gives a constraint of the maximum age of the lowermost sections of maximal 5000 years before present. Based on the success of our approach we have already extended the investigation to similar sites in the Eastern Alps, with promising first results suggesting the presence of millennia-old ice in an ice tunnel at Schladminger glacier.

The results of the study presented here demonstrate that, even today, cold-based ice still persists at summits of substantially lower altitude than $4000 \mathrm{~m}$ a.s.l., reaching several millennia in age. In a paleoclimatological context, our results indicate that Chli Titlis has likely been ice-covered for at least the last five millennia, although mass loss is ongoing today even at the summit. This finding is consistent with existing evidence suggesting for that time ice-free conditions at summit sites of comparable climatic and glaciological setting. Ultimately this shows that age constraints at cold-based summit glaciers constitute a significant, yet almost untapped, paleoclimate proxy, making the further exploration of these sites a worthwhile target.

Data availability. Underlying datasets of the stable water isotope analysis can be found at https://doi.pangaea.de/10.1594/PAN GAEA.885082 (Bohleber et al., 2018).

Competing interests. The authors declare that they have no conflict of interest.

Acknowledgements. We gratefully acknowledge the support of the Bergbahnen Titlis-Engelberg, in particular the help of Christoph Bissig and Peter Reinle. Likewise we acknowledge the support of the Dachstein Gletscherbahn Ramsau. Part of this work was performed under the project "Cold Ice" funded by the Austrian Science Fund (FWF): P 29256-N36. Financial support was provided to Pascal Bohleber by the Deutsche Forschungsgemeinschaft (BO 4246/1-1, BO 4246/3-1). Johanna Kerch received funding by the Studienstiftung des deutschen Volkes and support by the Helmholtz Junior Research group VH-NG-802. We acknowledge financial support by Deutsche Forschungsgemeinschaft and Ruprecht-Karls-Universität Heidelberg within the funding programme Open Access Publishing. The Klaus-Tschira-Lab Mannheim is acknowledged for their support in radiocarbon analysis. We also thank Martina Schmidt and Michael Sabasch of the Institute of Environmental Physics, Heidelberg University, for their support with the stable water isotope analysis and Heiri Rufli for his help with the 2014 sampling. We are grateful to Karl Krainer, University of Innsbruck, for his assistance with the visual stratigraphy. We would like to especially thank and acknowledge our late colleague Dietmar Wagenbach, who had initiated our work at Chli Titlis and contributed his long-standing experience at the 
beginning of the project. We also would like to thank the reviewers, Benjamin Laabs, Richard Waller and Bryn Hubbard, for their help in improving the manuscript.

Edited by: Benjamin Smith

Reviewed by: Benjamin Laabs, Bryn Hubbard, and Richard Waller

\section{References}

Abermann, J., Kuhn, M., and Fischer, A.: Climatic controls of glacier distribution and glacier changes in Austria, Ann. Glaciol., 52, 83-90, 2011.

Alley, R. B.: Flow-law hypotheses for ice-sheet modeling, J. Glaciol., 38, 245-256, 1992.

Baroni, C. and Orombelli, G.: The alpine "Iceman" and Holocene climatic change, Quaternary Res., 46, 78-83, 1996.

Bohleber, P., Hoffmann, H., Kerch, J., Sold, L., and Fischer, A.: Stable water isotope record from block profiles in the ice tunnel at Chli Titlis glacier, Switzerland, Pangaea, https://doi.org/10.1594/PANGAEA.885082, 2018.

Bonani, G., Ivy, S. D., Hajdas, I., Niklaus, T. R., and Suter, M.: AMS $14 \mathrm{C}$ age determinations of tissue, bone and grass samples from the Ötztal Ice Man, Radiocarbon, 36, 247-250, 1994.

Duval, P., Ashby, M., and Anderman, I.: Rate-controlling processes in the creep of polycrystalline ice, J. Phys. Chem., 87, 40664074, 1983.

Eichler, J.: C-Axis Analysis of the NEEM Ice Core - An Approach based on Digital Image Processing, PhD thesis, Fachbereich Physik, Freie Universität Berlin, hdl:10013/epic.41621, 2013.

Faria, S. H., Weikusat, I., and Azuma, N.: The microstructure of polar ice. Part I: Highlights from ice core research, J. Struct. Geol., 61, 2-20, 2014.

Fischer, A., Markl, G., Schneider, H., Abermann, J., and Kuhn, M.: Glacier mass balances and elevation zones of Kesselwandferner, Ötztal Alps, Austria, 1952/1953 to 2012/2013, https://doi.org/10.1594/PANGAEA.818757, 2014.

Fischer, A., Helfricht, K., and Stocker-Waldhuber, M.: Local reduction of decadal glacier thickness loss through mass balance management in ski resorts, The Cryosphere, 10, 2941-2952, https://doi.org/10.5194/tc-10-2941-2016, 2016.

Fischer, M., Huss, M., and Hoelzle, M.: Surface elevation and mass changes of all Swiss glaciers 1980-2010, The Cryosphere, 9, 525-540, https://doi.org/10.5194/tc-9-525-2015, 2015.

Gilbert, A. and Vincent, C.: Atmospheric temperature changes over the 20th century at very high elevations in the European Alps from englacial temperatures, Geophys. Res. Lett., 40, 2102 $2108,2013$.

Gow, A. J. and Williamson, T.: Rheological implications of the internal structure and crystal fabrics of the West Antarctic ice sheet as revealed by deep core drilling at Byrd Station, Geol. Soc. Am. Bull., 87, 1665-1677, 1976.

Grosjean, M., Suter, P. J., Trachsel, M., and Wanner, H.: Ice-borne prehistoric finds in the Swiss Alps reflect Holocene glacier fluctuations, J. Quaternary Sci., 22, 203-207, 2007.

Haeberli, W.: Eistemperaturen in den Alpen, Zeitschrift für Gletscherkunde und Glazialgeologie, 11, 203-220, 1976.
Haeberli, W. and Alean, J.: Temperature and accumulation of high altitude firn in the Alps, Ann. Glaciol., 6, 161-163, 1985.

Haeberli, W., Iken, A., and Siegenthaler, H.: Glaziologische Aspekte beim Bau der Fernmelde-Mehrzweckanlage der PTT auf dem Chli Titlis, VAW Mitt, 41, 59-75, 1979.

Haeberli, W., Frauenfelder, R., Kääb, A., and Wagner, S.: Characteristics and potential climatic significance of'miniature ice caps"(crest-and cornice-type low-altitude ice archives), J. Glaciol., 50, 129-136, 2004.

Hoelzle, M., Darms, G., Lüthi, M. P., and Suter, S.: Evidence of accelerated englacial warming in the Monte Rosa area, Switzerland/Italy, The Cryosphere, 5, 231-243, https://doi.org/10.5194/tc-5-231-2011, 2011.

Hoffmann, H., Preunkert, S., Legrand, M., Leinfelder, D., Bohleber, P., Friedrich, R., and Wagenbach, D.: A New Sample Preparation System for Micro-14C Dating of Glacier Ice with a First Application to a High Alpine Ice Core from Colle Gnifetti (Switzerland), Radiocarbon, 1-17, https://doi.org/10.1017/RDC.2017.99, 2017.

Hoffmann, H. M.: Micro radiocarbon dating of the particulate organic carbon fraction in Alpine glacier ice: method refinement, critical evaluation and dating applications, $\mathrm{PhD}$ thesis, Heidelberg University, 2016.

Hormes, A., Müller, B. U., and Schlüchter, C.: The Alps with little ice: evidence for eight Holocene phases of reduced glacier extent in the Central Swiss Alps, Holocene, 11, 255-265, 2001.

Hubbard, B., Cook, S., and Coulson, H.: Basal ice facies: a review and unifying approach, Quaternary Sci. Rev., 28, 1956-1969, 2009.

Ivy-Ochs, S., Kerschner, H., Maisch, M., Christl, M., Kubik, P. W., and Schlüchter, C.: Latest Pleistocene and Holocene glacier variations in the European Alps, Quaternary Sci. Rev., 28, $2137-$ 2149, 2009.

Joerin, U., Nicolussi, K., Fischer, A., Stocker, T., and Schlüchter, C.: Holocene optimum events inferred from subglacial sediments at Tschierva Glacier, Eastern Swiss Alps, Quaternary Sci. Rev., 27, 337-350, 2008.

Keck, L.: Climate significance of stable isotope records from Alpine ice cores, PhD thesis, University of Heidelberg, 2001.

Knight, P. G.: The basal ice layer of glaciers and ice sheets, Quaternary Sci. Rev., 16, 975-993, 1997.

Kutschera, W. and Müller, W.: "Isotope language" of the Alpine Iceman investigated with AMS and MS, Nucl. Instrum. Meth. B, 204, 705-719, 2003.

Lorrain, R. and Haeberli, W.: Climatic change in a high-altitude alpine area suggested by the isotopic composition of cold basal glacier ice, Ann. Glaciol., 14, 168-171, 1990.

May, B.: Radiocarbon microanalysis on ice impurities for dating of Alpine glaciers, PhD thesis, University of Heidelberg, 2009.

Nicolussi, K. and Patzelt, G.: Untersuchungen zur holozanen Gletscherentwicklung von Pasterze und Gepatschferner (Ostalpen). Mit 41 Abbildungen, Zeitschrift fur Gletscherkunde und Glazialgeologie, 36, 1-88, 2000.

Obleitner, F. and Spötl, C.: The mass and energy balance of ice within the Eisriesenwelt cave, Austria, The Cryosphere, 5, 245257, https://doi.org/10.5194/tc-5-245-2011, 2011.

Ødegård, R. S., Nesje, A., Isaksen, K., Andreassen, L. M., Eiken, T., Schwikowski, M., and Uglietti, C.: Climate change threatens archaeologically significant ice patches: insights into their age, internal structure, mass balance and climate sensitivity, The 
Cryosphere, 11, 17-32, https://doi.org/10.5194/tc-11-17-2017, 2017.

Oeschger, H., Schotterer, U., Stauffer, B., Haeberli, W., and Röthlisberger, H.: First results from Alpine core drilling projects, Zeitschrift für Gletscherkunde und Glazialgeologie, 13, 193208, 1977.

Olefs, M. and Lehning, M.: Textile protection of snow and ice: Measured and simulated effects on the energy and mass balance, Cold Reg. Sci. Technol., 62, 126-141, 2010.

Ramsey, C. B.: Radiocarbon calibration and analysis of stratigraphy: the OxCal program, Radiocarbon, 37, 425-430, 1995.

Schöner, W., Weyss, G., and Mursch-Radlgruber, E.: Linkage of cave-ice changes to weather patterns inside and outside the cave Eisriesenwelt (Tennengebirge, Austria), The Cryosphere, 5, 603616, https://doi.org/10.5194/tc-5-603-2011, 2011.

Stuiver, M. and Polach, H.: Discussion: Reporting of ${ }^{14} \mathrm{C}$ data, Radiocarbon, 19, 355-363, 1977.

swi: Swissimage, available at: https://shop.swisstopo.admin.ch/de/ products/images/ortho_images/swissimage25 (last access: 5 December 2017), 2017a. swi: Digital height model DHM 15/200 of Swisstopo, available at: https://shop.swisstopo.admin.ch/de/products/height_models/ dhm25200 (last access: 6 December 2017), 2017b.

Uglietti, C., Zapf, A., Jenk, T. M., Sigl, M., Szidat, S., Salazar, G., and Schwikowski, M.: Radiocarbon dating of glacier ice: overview, optimisation, validation and potential, The Cryosphere, 10, 3091-3105, https://doi.org/10.5194/tc-10-30912016, 2016.

Wagenbach, D., Bohleber, P., and Preunkert, S.: Cold alpine ice bodies revisited: What may we learn from their isotope and impurity content?, Geogr. Ann. A, 94, 245-263, 2012.

Zemp, M., Gärtner-Roer, I., Nussbaumer, S., Hüsler, F., Machguth, H., Mölg, N., Paul, F., and Hoelzle, M. (Eds.): Global Glacier Change Bulletin No. 1 (2012-2013), 230 pp., ICSU(WDS)/IUGG(IACS)/UNEP/UNESCO/WMO, World Glacier Monitoring Service, Zurich, Switzerland, 2015. 